\title{
“Jobs that Really Matter": Critical Reflections on Changes in Academic Life during/after the Covid-19 Pandemic
}

\author{
Veronika Kalmus \\ University of Tartu, Estonia, veronika.kalmus@ut.ee, \\ https://www.ae-info.org/ae/Member/Kalmus_Veronika
}

\begin{abstract}
The prioritisation of the coronavirus pandemic in the public sphere has resonated in the field of sciences, with Covid-19 occupying the interest of many researchers in various disciplines. This article aims to analyse features of interpersonal and institutional discourses, published data, and the author's observations to reflect critically upon the impact of Covid-19 on academic life and sketch some trends in the field of sciences. The analysis demonstrates that Covid-19 serves as an accelerator for science; this process, however, is asynchronous across countries, disciplines, and research streams. The "Covid-isation" of research systems reinforces the instrumentalisation and projectification of science and creates intra-institutional hierarchies. The coronavirus crisis amplifies existing inequalities and prompts the double movement of acceleration versus deceleration. In the potential social morphogenesis in the field of science, the role of the humanities and social sciences scholars in asking critical questions and facilitating meta-reflexivity becomes paramount.
\end{abstract}

Keywords: coronavirus, COVID-19, science, social acceleration, neoliberal academia, critical theory, discourses, double movement

Acknowledgement: I am grateful to Andre Uibos for insightful comments on an earlier version of this article.

\section{Introduction}

I am at the hairdresser's, and a topic for small talk is offered to me. It is late spring in 2020, and the Covid-19 pandemic is an unavoidable subject in any human encounter. Amid our conversation, the hairdresser says: "This crisis revealed those jobs that really matter". Among "those jobs" she lists medical workers, police officers, people working in grocery stores and food production, and scientists working on Covid-19 treatment and vaccines. She does not mention hairdressers or social scientists.

I have opened this article with the paraphrase of the well-known sentence ("I am at the barber's...") in Roland Barthes' $(1972,115)$ immortal Mythologies. The small talk at the hairdresser's and many other topically related pieces of private and public discourses I have heard or read since the outbreak of the pandemic have inspired me to explore the meanings and ideologies, even myths, embodied in those utterances, announcements, and much broader discursive and social practices. In what follows, I will analyse some prominent features of interpersonal and institutional discourses, published data, and my own observations to reflect critically upon the impact of Covid-19 on academic life and sketch some trends in the field of sciences. Most of these trends can metaphorically be labelled as "double-edged swords", even "double movements" in Karl Polanyi's (1944) sense. The genre of my piece is neither a classical analytical study, nor any sort of manifesto. This article is, rather, a reflexive contemplation, 
organised around some macro-level generalisations of my individual micro-level observations that form its sections.

\section{And Nothing Else Matters}

As we may observe, the media and public discourses changed overnight in the infamous year of 2020. Covid-19-related news suddenly dominated the broadcasts, newspapers, portals, and social media to an extent that - both in terms of amplitude and duration - no topic has attained in the last decades. The prioritisation of the pandemic in the public sphere resonated in the field of sciences: Covid-19 instantaneously occupied the interest of many researchers - not just virologists, epidemiologists, and other medical scientists, but widely beyond.

On the individual and research group level, we could see thousands of journal articles and numerous books on Covid-19 and its impacts getting published in a few months. Countless webinars and online conferences on the pandemic were initiated. In proposal writing, many researchers were able to react to the new situation and reorient their interests within a few weeks. For instance, in spring 2020, three out of seven proposals submitted to the University of Tartu by PhD student candidates in Media and Communication focused on Covid-19 and the media. On the institutional side, we saw a rapid opening of new calls, and extraordinary levels of public and private funding targeted at finding solutions to the Covid-19 pandemic and its impacts. No doubt, this is an impelling force and a refreshing development for science.

But there is another side to the coin, the bloody edge of the same sword. The prioritisation of Covid-19-related topics, already labelled the "Covid-isation" of research systems (Frontiers 2020, 25), brought along the overshadowing, de-prioritising and even depreciation of other topics and research streams, including basic and theoretical studies. As an example, I quote a press release by the Estonian Research Council from March 18, 2020. When publishing the list of 32 applied research projects that had just been approved for funding, the Research Council considered it necessary to add an apology:

This Call took place before the virus outbreak causing the current emergency; therefore, the reverberated topics have been motivated by pre-emergency problems, and will rise among the priorities again, when the society returns to the conventional rhythm of life [emphasis added].

Obviously, this piece of institutional discourse includes an assumption that all those 32 newly funded research topics (including, for example, the impact of excessive salt consumption on human health) were not among the priorities for research in spring 2020. In being discernibly motivated by the perceived public pressure to focus only on Covid19, the Research Council followed an urge to justify their decision to fund 32 presumably redundant and pointless topics.

On the global level, according to a report by Frontiers ${ }^{1}$ (2020), one fourth of respondents stated that the funding had been redirected from their area (less funding available), while only $6 \%$ admitted that the funding had increased in their area (more funding available). This suggests that the surge in research funding levels has indeed been concentrated in a few specific areas. Furthermore, nearly half of the international research community (47\%) were concerned about the long-term impact on funding, supposing that the funding would be redirected from their area in the future.

\footnotetext{
${ }^{1}$ Based on an online survey of 25,307 researchers conducted in May and June 2020.
} 
Interestingly, geologists, biologists, and environmental and materials scientists expressed the most concerns about future funding (more than $50 \%$ believed that less funding would be available). While researchers in the fields of medicine and the humanities and social sciences were placed in the middle (with $46-47 \%$ comprising pessimists), computer scientists expressed the lowest level of pessimism (34\%) and the highest level of optimism (19\% expecting more funding to be available). It is less surprising that pessimism about future funding shows political clustering in responses, with researchers from countries with prevailing neoliberal ideological regimes and/or unstable funding mechanisms (e.g. Australia, the UK, the US, Chile and Mexico) being the least optimistic (at least half of respondents expected the funding available to them to be reduced) and a small group of countries with stable funding mechanisms (e.g. Norway, China and Japan) standing out as the most confident about future funding.

\section{Make Science Great Again}

Another double-sided trend in academic life springs from the prioritisation of the pandemic in the public sphere. On the positive side, the need for evidence-based governance and policymaking was loudly acknowledged in many countries, and the value of $\mathrm{R} \& \mathrm{D}$ and the status of scientists rocketed upwards. According to Kamila Markram, CEO of Frontiers, "Science has been thrust into the spotlight" (Frontiers 2020, 3). Science is being made great again.

On the more problematic side, the same tendency may lead to the further instrumentalisation of science, already described by Jean-François Lyotard (1979) in his Postmodern condition: A report on knowledge. Through instrumentalisation, the goal of truth in science is replaced by "performativity" and efficiency in service of the state or capital. This, in turn, is related to increasing pragmatisation of science, in which more and more emphasis is put on the practical use and exploitation of scientific results as rapidly as possible. The instrumentalisation and pragmatisation of science is perfectly in line with the process known as "projectification", seen as "a structural trajectory in corporate re-structuring", and theorised as "a cultural and discursive phenomenon" (Packendorff and Lindgren 2014, 7). In academic life, project-oriented discursive modes of justification legitimise projectified research as a task-specific, deliverabledriven, and time-limited form of working. Projectification is closely and causally linked to the dominance of marketisation under the prevailing conditions of capitalism (Nies and Sauer 2018,60), creating new forms of power governed by measuring and audits, indicators, and algorithms (Shore and Wright 2015) as well as the subjective feeling of the accelerating life on a personal as well as professional level (Kalmus and Opermann 2020). On a more general level, instrumentalisation and projectification raise the value dilemma regarding the autonomy versus dependency of science vis-à-vis the demands of the state and the market.

\section{Science Goes Online}

As the third prominent trend, the coronavirus spring brought along the accelerated development and appropriation of various digital methods and online platforms. In connection with this encouraging development, new ethical and legal issues emerged. For instance, questions on whether one or another platform was safe and secure, or 'GDPR-proof' (in European contexts), demanded urgent practical solutions and spurred ethical deliberations among researchers and officials.

While digital methods favoured, or at least enabled, research on many topics and with some social groups, the lockdown measures hindered or even stopped research with certain often disadvantaged social groups (e.g. young children or the elderly) 
and/or with face-to-face methods. This double-sided tendency thus induces a critical question: is the forced proliferation of digital methods a rising tide, lifting all boats in the longer run, or will it ultimately increase inequality between research groups and individual researchers? Will this mode of acceleration eventually synchronise or desynchronise the development of various disciplines and research streams?

\section{The Winner Takes It All}

While the coronavirus crisis prompted the growing prestige and accelerated development of science as such, these developments brought along increasing competitiveness and inequality in academic life. Three double-sided trends, outlined above, signal the emergence of 'winners' and 'losers' on new bases - disciplines, topics, and their pragmatic use value, as well as research methods.

More subtly, the lockdown measures amplified the existing individual-level handicaps in science, based on parenthood and the extent of teaching obligations. In the coronavirus crisis, the blurring and convergence of different social spaces in the locale of the home, accompanied by the "convergence of time periods dedicated to specific activities" - the processes being previously advanced by neoliberalism (Fuchs 2020, 378-379) - was indeed taken to its extreme. For many academics, the home became office or lab, lecture room, conference hall and library, and, at the same time, kindergarten, school, gym, and place for culture consumption. The convergence of timespace in the home, however, affected individual academics differently, depending on their life cycle, family status and professional (research- versus teaching-centred) profile. While for some the cancellation of on-site conferences, meetings and lectures, and the lack of ability to socialise with colleagues and students meant "the looming huge gap in our professional and personal lives" [private e-mail communication], for others the simultaneous effort of home-schooling their kids and switching, lightning-fast, to web-based university teaching resulted in total overburdening. 


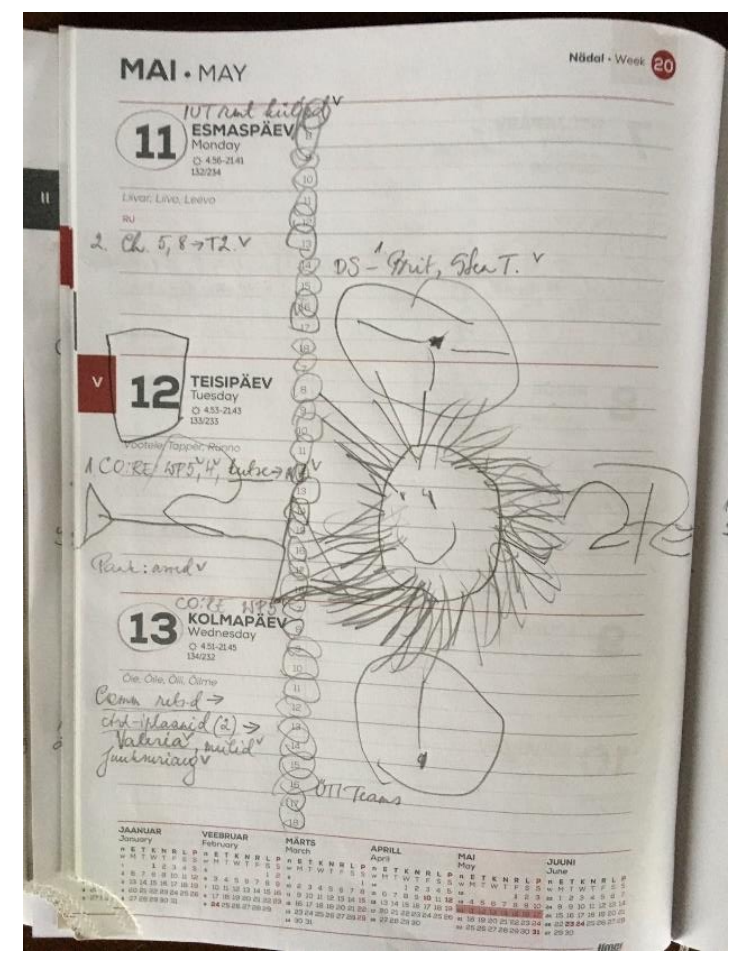

Figure 1: The calendar of a home-schooling academic in May 2020 (with a reproduction of the mediated image of the Covid- 19 virus by a 6 -year-old)

For academics, similarly to many other professions, the coronavirus crisis has been, indeed, "a process of radical mass housewifization" (Fuchs 2020, 380). We may even term it "forced houseparentisation", as in many cases, the convergence of time-space and different social roles in the locale of home has affected parents of both sexes almost equally. Figure 1 illustrates how the forced home-schooling of a 6-year-old in spring 2020 has literally occupied the calendar of a professor/parent.

Unequal conditions for working from home will result, sooner or later, in imbalanced performance in the highly competitive field of research. For instance, when deprived of childcare for months during the lockdown, a female professor admitted that all her time management efforts "went into teaching" [private e-mail communication] and she was lagging behind schedule for writing a monograph.

On the institutional level, such handicaps have seldom been realised and considered. The Estonian Research Council, for example, generously decided to extend the deadline for new project proposals by one week:

[...] in complying with the wishes of scientists in the parent's role, we have extended the deadline for PSG/PRG/PUTJD applications by one week until April 7 [E-mailed announcement, March 16, 2020; emphasis added].

Single short-term gestures like this, while fulfilling the function of acknowledging the problem, help little, alas, in terms of mitigating the intra-professional inequalities in the long run and on a wider scale.

On the global level, the report by Frontiers (2020) revealed great variation in academics' perception of work disruption depending on their country location - particularly in terms of support they received to help them work from home. South American countries (Argentina, Chile, and Brazil) appeared to have been hardest hit, with almost a 
third of researchers reporting that their working practices had been affected by the pandemic.

For a longer perspective, we are left with a question: will this crisis lead to a greater consideration and mitigation of inequality and handicaps in science, or will it contribute to their normalisation and perpetuation?

\section{Conclusions}

By summarising the trends sketched in this article, we may conclude that in general, Covid-19 serves as an accelerator for science as an institution. We have seen a lightning-fast opening of new calls and extraordinary public and private funding targeted at finding solutions to the pandemic and its impacts and satisfying the need for evidencebased governance and policymaking, promptly acknowledged in many countries. We have observed the academic community's reacting to this sudden challenge and opportunity swiftly and self-forgetfully by re-orienting their research interests within a few weeks and presenting and publishing on the new topic faster than ever before. The lockdown measures, furthermore, prompted the accelerated development and appropriation of digital methods and online platforms. This acceleration process, however, has not been synchronous across countries, disciplines, and research streams. The "Covid-isation" of research systems reinforces the processes of instrumentalisation and projectification of science, creating intra-institutional hierarchies. This, in turn, leads to increasing competition in many disciplinary fields and the rising levels of precarity and insecurity among the academic community.

On the individual level, the coronavirus crisis rather amplifies existing inequalities and brings along the double movement of deceleration versus acceleration. For some, the coronavirus crisis indeed means "forced deceleration" as Hartmut Rosa (2020) has argued. For others, the lockdown measures, leading to the convergence of time-space and different social roles in the locale of home and forced houseparentisation, increase the number of activities and experiences per unit of time, and thus bring about an extreme acceleration of personal time and life. Academics with heavy teaching loads and profoundly projectified researchers have no privilege of postponing some tasks to slow down temporarily. This, in turn, results in total overburdening and handicapped performance in the highly competitive field of research.

To account for the tendencies sketched out in this article from a meta-level theoretical perspective, we can see Covid-19, in Margaret Archer's (2013) terms, as an external generative mechanism, which may, potentially, initiate transformative processes or social morphogenesis in the field of science. Double movements are natural in the course of social morphogenesis; however, meta-reflexivity is needed to develop higher diversity and to avoid cultural clashes (Masso et al. 2020). To make our jobs matter, in asking critical questions about far-reaching impacts of the pandemic on science and facilitating meta-reflexivity among academics, the role of scholars in the humanities and social sciences becomes paramount.

\section{References}

Archer, Margaret S., ed. 2013. Social Morphogenesis. Dordrecht: Springer.

Barthes, Roland. 1972. Mythologies. Translated by Annette Lavers. London: Paladin.

Frontiers. 2020. The Academic Response to Covid-19: A Survey Report. October. Accessed November 11, 2020. https://www.frontiersin.org/articles/10.3389/fpubh.2020.621563/pdf

Fuchs, Christian. 2020. Everyday Life and Everyday Communication in Coronavirus Capitalism. tripleC: Communication, Capitalism \& Critique 18 (1): 375-399. Accessed March 14, 2021. https://www.triple-c.at/index.php/tripleC/article/view/1167 
Kalmus, Veronika and Signe Opermann. 2020. Personal Time Capital in the Digital Society: An Alternative Look at Social Stratification among Three Generations of Highly Skilled Professionals in Estonia. Trames: Journal of the Humanities and Social Sciences 24 (1): 3-25. Accessed March 14, 2021. https://www.kiri.ee/public/trames pdf/2020/issue 1/Trames-1-2020-3-25.pdf

Lyotard, Jean-François. 1979. La condition postmoderne: rapport sur le savoir. Paris: Minuit. Masso, Anu, Marju Lauristin, Signe Opermann and Veronika Kalmus. 2020. Applying the Morphogenetic Perspective for the Analysis of Estonian Social Transformations. In $R e$ searching Estonian Transformation: Morphogenetic Reflections, edited by Veronika Kalmus, Marju Lauristin, Signe Opermann and Triin Vihalemm, 1-31. Tartu: University of Tartu Press.

Nies, Sarah and Dieter Sauer. 2018. Work - More than Employment? Critique of Capitalism and the Sociology of Work. In Capitalism and Labor: Towards Critical Perspectives, edited by Klaus Dörre, Nicole Mayer-Ahuja, Dieter Sauer and Volker Wittke, 44-70. Frankfurt: Campus Verlag.

Packendorff, Johann and Monica Lindgren. 2014. Projectification and its Consequences: Narrow and Broad Conceptualisations. SAJEMS Special Issue 17: 7-21.

Polanyi, Karl. 1944. The Great Transformation: The Political and Economic Origins of Our Time. New York: Rinehart.

Rosa, Hartmut. 2020. Interview. TAZ, 25 March 2020. Accessed March 19, 2021. https://taz.de/Soziologe-HartmutRosa-ueber-Corona/!5673868/

Shore, Cris and Susan Wright. 2015. Governing by Numbers: Audit Culture, Rankings and the New World Order. Social Anthropology 23 (1): 22-28.

\section{About the Author}

Veronika Kalmus

Veronika Kalmus is Professor of Sociology at the Institute of Social Studies, University of Tartu, Estonia. Her research focuses on mediatisation, socialisation, generations, social transformations, social acceleration, value orientations, discourses, and mental structures. She is a member of the Film, Media and Visual Studies section in Academia Europaea. 